\title{
Young male with chest pain and abnormal T-waves
}

\author{
Amrithanand Velluridathil Thazhathidathil, ${ }^{1}$ Naman Agrawal, ${ }^{2}$ Roshan Mathew ${ }^{1}$ \\ ${ }^{1}$ Department of Emergency Medicine, AIIMS, New Delhi; ${ }^{2}$ Department of Emergency Medicine, AIIMS, \\ Rishikesh, India
}

\begin{abstract}
Early recognition of ECG signs of acute coronary syndrome is essential for prompt treatment. But presentation with atypical ECG changes constitute a diagnostic challenge. We here report a case of 23 -year-old male who presented with chest pain having atypical ECG changes with hyper-acute $\mathrm{T}$ waves called de Winters $\mathrm{T}$ wave. This is a rare presentation of patient with acute Left Anterior Descending artery occlusion. Some authors propose that de Winters pattern should be considered as "STEMI Equivalent".
\end{abstract}

\section{Introduction}

Diagnosis of ST- segment elevation myocardial infarction is time sensitive. Even the atypical ECG presentations should never be missed. De Winters ECG is a kind of atypical pattern characterized by ST depressions and peaked T waves. ${ }^{1}$ It is a rare presentation of proximal Left Anterior Descending artery occlusion. ${ }^{2}$

\section{Case}

A 23-year-old male presented to emergency with complaint of anterior chest discomfort for last 2 hours. The pain was retrosternal

\footnotetext{
Correspondence: Roshan Mathew, India Institute of Medical sciences, 110029, Delhi, India

Tel.: +91.7838677063.

E-mail: roshmat15@gmail.com

Key word: Acute coronary syndrome; ECG; emergency.

Conflict of interest: No one. This work was not supported by any grant.

Contributions: AV, NA, RM were involved in managing the case, AV wrote the 1st draft of the manuscript, NA and RM did critical revision of the manuscript.

Ethics approval and consent to participate: The manuscript does not contain any elements that would allow the recognition of the patient.

Received for publication: 11 December 2019.

Accepted for publication: 28 February 2020.

This work is licensed under a Creative Commons Attribution 4.0 License (by-nc 4.0).

C Copyright: the Author(s), 2020

Licensee PAGEPress, Italy

Emergency Care Journal 2020; 16:8751

doi:10.4081/ecj.2020.8751
}

in location, acute onset, crushing type, no radiation and not associated with any aggravating or relieving factors. It was not associated with diaphoresis, nausea, dyspnea, syncope, cough or any leg swelling. There was no previous comorbidities and significant family history. He was non-smoker and non-alcoholic. On examination, he had a pulse rate of $90 / \mathrm{min}, \mathrm{BP}-136 / 80 \mathrm{mmHg}, \mathrm{RR}-$ 20/min, $\mathrm{SpO}_{2-} 98 \%$ on room air. The cardiovascular and respiratory examination were also normal. A twelve-lead ECG was ordered for the patient (Figure 1) which revealed a rate of $85 / \mathrm{min}$ normal rhythm, axis and interval. It shows upsloping ST depression with tall upright symmetrical T waves in leads V2 and V3 along with ST depression in lead 2, 3 and aVF and ST segment elevation in aVR (Figure 2). The above $\mathrm{T}$ wave pattern is consistent with De Winter's T wave which suggest critical Left Anterior Descending (LAD) artery occlusion. The initial troponin level was $0.071 \mathrm{mcg} / \mathrm{ml}$ and the repeat levels increased to $2.24 \mathrm{mcg} / \mathrm{ml}$. The patient was given antiplatelet and admitted in cardiology where a coronary angiogram done which revealed a proximal lesion in LAD. The ECG changes normalized after the Percutaneous intervention (Figure 3).

\section{Discussion}

The characteristic ECG pattern was first reported by De Winter and Wellens in 2008 in which they described it in 2\% of patients with acute LAD occlusion. The ECG of the patient demonstrated upsloping ST depression at J point followed by tall, positive symmetrical $\mathrm{T}$ waves. The description was consistent with ECG in our case. The original report of de Winters had suggested that this ECG changes does not change or evolve until culprit artery had been opened, but since then cases have reported STEMI morphology may precede or follow the de Winter pattern. ${ }^{3}$ Another case series by Verouden et al found this in 35 of 1890 patient requiring PCI for

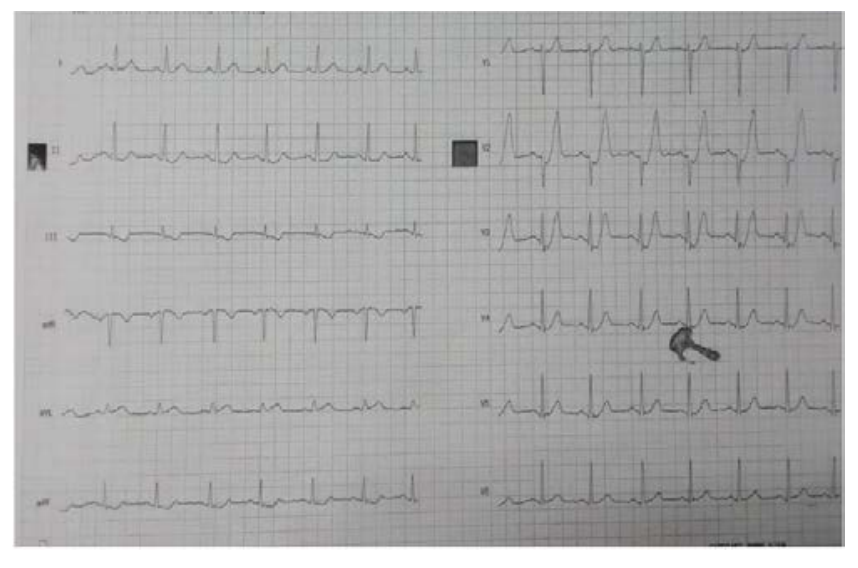

Figure 1. ECG of the patient. I, II, III : Limb Leads; aVR, aVL, aVL: Augmented Limb leads; V1-V6: Chest leads. 


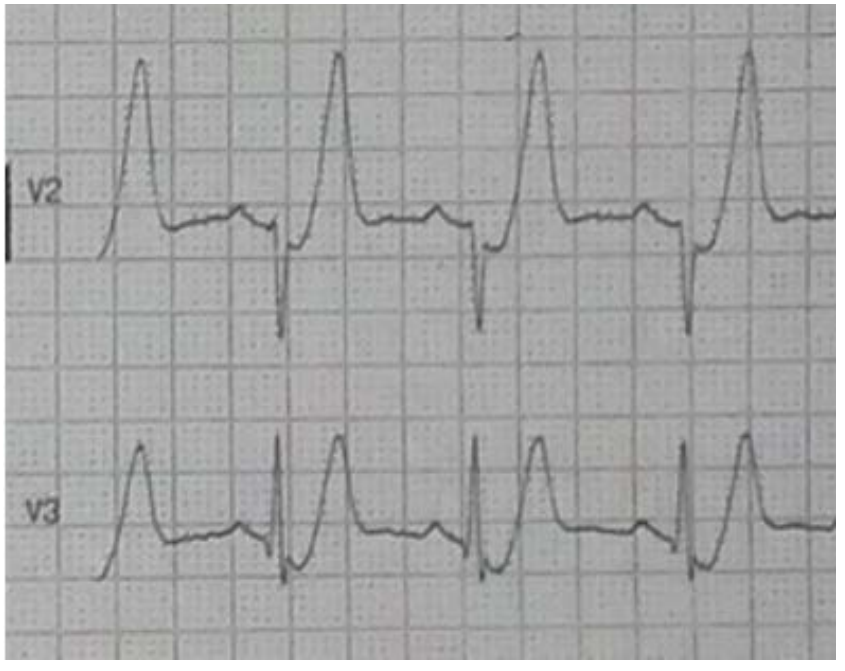

Figure 2. A close-up image of lead V2 V3 highlighting the upsloping ST depression and tall T waves. V2-V3: Chest leads.

LAD occlusion. The profile of patients with this pattern were

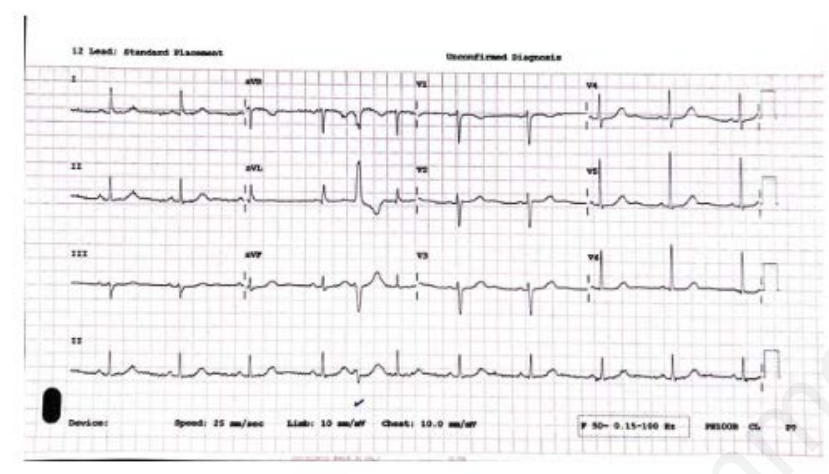

Figure 3. ECG of the patient post- PCI. mainly young males with higher incidence of hypercholesterolemia. ${ }^{4}$

The main criteria for diagnosis are upsloping ST segment depression $>1 \mathrm{~mm}$ at the $\mathrm{J}$ point along with tall symmetric $\mathrm{T}$ waves in the precordial leads. There was absence of ST elevation in precordial leads. Recognizing such ECG pattern is clinically important since it presents without obvious ST segment elevation and may lead to under treatment. Immediate recognition of this condition is required, and such patient should receive an emergency reperfusion preferably with Percutaneous Coronary Intervention (PCI) or thrombolysis when timely PCI is not available.

\section{Conclusion}

The De Winters ECG changes signifies extremely severe coronary pathology with a high mortality. Even though it is a rare presentation, it should never be missed. Recognition is crucial for timely reperfusion of the patient. Knowledge about this specific ECG changes is necessary for emergency physicians for timely recognition, activation of cath lab and prompt treatment.

\section{References}

1. Lawner BJ, Nable JV, Mattu A. Novel patterns of ischemia and STEMI equivalents. Cardiol Clin 2012;30:591-9.

2. De RW, Verouden NJ, Wellens HJ, Wilde AA. A new ECG sign of proximal LAD occlusion. N Engl J Med 2008;359:2071-3.

3. Goebel M, Bledsoe J, Orford JL, et al. A new ST-segment elevation myocardial infarction equivalent pattern? Prominent $\mathrm{T}$ wave and J-point depression in the precordial leads associated with ST-segment elevation in lead aVr. Am J Emerg Med 2014;32:287.e5-287.e8.

4. Verouden NJ, Koch KT, Peters RJ, et al. Persistent precordial "hyperacute" T-waves signify proximal left anterior descending artery occlusion. Heart Br Card Soc 2009;95:1701-6. 